\title{
Need for continued tobacco industry monitoring
}

\author{
Lindsay Robertson
}

Department of Preventive and Social Medicine, University of Otago, Dunedin, New Zealand

\section{Correspondence to} Dr Lindsay Robertson, Department of Preventive and Social Medicine, University of Otago, Dunedin 9054, New Zealand;

l.robertson@otago.ac.nz

Check for updates

(c) Author(s) (or their employer(s)) 2022. No commercial re-use. See rights and permissions. Published by BMJ.

To cite: Robertson L. Tob Control 2022;31:382.
In the reasonably short period of time- -10 yearsthat I've worked in tobacco control, the field has changed markedly. As the range of tobacco and nicotine products has expanded and become much more complex, so too has the landscape of policy actors. There are now larger numbers of organisations-including vaping industry trade associations and consumer groups (some of which have been supported by tobacco industry funding)-advocating for new nicotine products to be liberalised. Potential conflicts of interest are often less immediately apparent and more time consuming to ascertain.

The heightened complexity faced by those involved in policy making looks likely to continue for some time. The sheer rate at which new nicotine products, and new versions of those products, are being developed undoubtedly constrains regulators' ability to assess evidence of different nicotine products' health effects. As an example, since the reintroduction of heated tobacco products (HTPs) in 2014, tobacco companies have continued developing new versions and there are now at least four different HTP types each using a different heating method. In August 2021, Philip Morris International (PMI) launched its IQOS ILUMA, its first IQOS device to use an 'induction' rather than a blade heating method, which the company claimed would 'accelerate the achievement of a smoke-free future'. ${ }^{1}$ Yet there is no evidence about the longterm health effects of each type of device, or the HTP category as a whole, ${ }^{2}$ and much of the existing research has been conducted by the tobacco industry or groups they have funded.

In the near future, there is likely to be a further accumulation of research supporting new 'reducedrisk' nicotine products that has been financed indirectly by the tobacco industry. The Foundation for a Smoke-Free World (FSFW), still solely funded by PMI, has now provided millions of dollars in funding to dozens of researchers, advocacy and media organisations. While many resulting outputs may cite the FSFW as the funder, some decision makers and those involved in policy development may remain unaware of authors' potential conflicts of interest.

In my view, the future of tobacco control depends in large part on the sector's capacity to continue monitoring and exposing tobacco companies' activities, particularly their attempts to influence policy (whether directly or through engaging with vaping industry associations, consumer groups or other third parties) and to skew the evidence base in support of new nicotine products. Continued monitoring of the tobacco industry will enable the sector to stay abreast of tobacco companies' future plans, such as their potential diversification into areas such as cannabis, and could also help ensure the successful adoption of bold new tobacco control policies, such as New Zealand's Smokefree 2025 Plan, a policy that could set an important precedent for creating a genuinely smoke-free future.

Contributors $L R$ is the sole contributor to this commentary.

Funding LR is supported by a fellowship from the New Zealand Heart Foundation and a Royal Society Te Apārangi Marsden FastStart grant (U002028).

Competing interests None declared.

Patient consent for publication Not required.

Ethics approval This study does not involve human participants.

Provenance and peer review Commissioned; internally peer reviewed.

ORCID iD

Lindsay Robertson http://orcid.org/0000-0001-8383-9116

\section{REFERENCES}

1 Philip Morris International. Philip Morris international launches new IQOS ILUMA in Japan to accelerate the achievement of a smoke-free future (press release), 2021. Available: https://www.pmi.com/mediacenter/press-releases/press-release-details?newsld=24261 [Accessed 17 Aug 2021].

2 World Health Organization. Heated tobacco products: a brief. Geneva: World Health Organization, 2020. https://www.euro.who. int/_data/assets/pdf_file/0008/443663/Heated-tobacco-productsbrief-eng.pdf 